\title{
Simultaneous Interpreting of the Figures of Speech: Problems and Solutions
}

\author{
Abdel-Rahman Adam Hamid* \\ Department of English and Translation College of Science and Arts, Qassim University, Ar Rass, Saudi Arabia \\ *Corresponding Author: Abdel-Rahman Adam Hamid, Department of English and Translation College \\ of Science and Arts, Qassim University, Ar Rass, Saudi Arabia
}

\begin{abstract}
Figures of speech are very important components of the literary language in all natural languages. And speech is the first form of language practiced by humans. As modern international, regional and local or national relations are conducted and developed by holding conferences, and these are mainly delivered in speeches, which are the material of study herein, interpreters may be confronted with figures of speeches while translating instantly in these conferences. So, the present study is an attempt to investigate the advantages and problems that are encountered by the interpreter while fulfilling his/her job. And due to the misleading literal translation or the non-existence of a suitable cultural equivalent, for figures of speech, in a target language, interpreting these said figures of speech need to be analysed leaving their interpretation to the ability of each interpreter. This means, advanced interpreters find always, even not one hundred per cent accurate, a solution to translate a speech, we will not suggest a comprehensive method or theory for finding immediate solutions, on the contrary we leave the style and intelligence of each interpreter lead him/her, through the seas of nameless words, the waves of units and sentences to the coasts of safety accurate translation, avoiding thus seas of tears or a deaf and loud interpretation. However, the data suggested and examples given are analysed in the light of general theories and interpretation strategies. Someone may consider the method of analysis as technique and methodology suggested to interpreters or the reader of this study. The research findings pointed out that the main problem may be the literal interpretation or the misleading cultural equivalences given by a trainee or a non-deep experience interpreter. So these findings suggest for the beginner or trainee translator to avoid literal translations.
\end{abstract}

Keywords: Interpreter, Metaphor, Alliteration, Euphemism, Oxymoron, Shortcoming, Compensation,

\section{INTRODUCTION}

The present study is an attempt to forward a linguistic analysis of the effect of interpreting figures of speech English/French/Arabic. The researcher of this article will try to draw an analytic strategy to be followed by interpreters, but not a comprehensive one. It will forward some cases that maybe faced by interpreters in real cases, political conferences, press conferences, meetings translated simultaneously or instantaneously; or similar cases in which he/she may be called. There will be some suggestions of solutions or steps to take to avoid interpreting figures of speech in a false manner.

The study is also a plea of interpreting: The interpreter will lay down and may convey a speech or an oral address or discourse, in real time, instantaneously or immediately, respecting the tone, rhythm, speed, culture, and stress of the speaker.

As the figures of speech are found abundantly in the literary language, the examples studied here in after don't concern how to interpret literary speech or units, or texts, instead they are examples analysed with an attempt to see how some figures of speech may be interpreted from English/French/Arabic once existed in a speech. In fact, figures of speech are a wide and complex field that necessitate a broad study, however, the author will tackle them, namely: alliteration, metaphors, oxymoron, euphemism, onomatopoeia and specifically, or with focus drawn on their oral use, due to the fact that interpreting means the process of translating a speech, in real time immediately and simultaneously.

\section{Statement of the Problem}

There is an increase in the number of conferences, contacts on the international level, conflicts, treaties, commercial contacts etc... which make a huge increase and a need for translation and 
interpretation services. Some scholars and professional interpreters think of decreasing or increasing the number of the trainee interpreters, and the professional ones in an attempt for resolving problems such as those of figures of speech. Others claim the teaching of the figures of speech, idioms, proverbs, and the like, into the schools of translation as requirement or vital necessity.

However, the problem is not on the level of decreasing or increasing the number of translation students or learning terms by heart. Let us see what the analyses reveal to us as readers of the present study.

\section{STUDY QUESTIONS}

- What are the difficulties encountered by the interpreter while translating instantaneously a figure of speech?

- How can interpreting figures of speech be challenging in the framework of simultaneous interpretation of conferences?

- To what extend interpreting figures of speech is profitable when it is done professionally?

\section{STUdY HyPotheSES}

- There are difficulties encountered by the interpreter while translating instantaneously or simultaneously a figure of speech.

- Interpreting figures of speech can be challenging in the framework of simultaneous interpretation of conferences.

- Interpreting figures of speech is profitable when it is done professionally.

\section{LITERATURE REVIEW}

There are some works on the issue of figures of speech, in general. James Nolan conducted works and wrote a chapter on figures of speech and translating them, simultaneously, in: English/French and Spanish. However, there are insufficient works on figures of speech, especially trilingual ones and mainly in the field of interpretation. Figures of speech are normally conducted in the framework of literary works and prose.

As well there are differences on view points as regard to the method of interpreting figures of speech: should it be literally or by equivalences.

Some international schools of interpretation such as l'école supérieure d'interprétariat et de traduction, (L'ESIT) at Paris, proceed generally in the framework of what they call "La théorie du sens" (the theory of meaning): This method is contested by linguists who consider the meaning (semantics) as a branch of linguistics, so (L'ESIT) is rejecting linguistics and at the same time it adopts its theories and says: translation is a theory which practice is done outside the framework of linguistics. This is denied by, the researcher, translators, interpreters and scholars adopting linguistics methods. Anyway, the ESIT is a School known for its contribution in the question of interpretation and translation.

Other interpreters and translators don't focus on translation and interpretation away from the linguistic studies, which include: sociolinguistic theory, theories of pragmatics and some other approaches that consider meaning and word-to-word translation methods.

Finally, some scholars such as Newman P., in the UK handle the matter in the framework of linguistics. However, others like Nida E., in the USA link translation, in general, to culture. Some famous linguists don't even consider idioms, proverbs and figurative language as part of our cognitive system, so the figures of speech and idioms have no underplayed role in the generative grammar (see, Chomsky 1993).

\section{Material AND MethodS}

The investigation used herein consists of studying and analysing five types of figures of speech. Some examples and expressions are extracted from the Oxford Dictionary of Idioms (2005) ${ }^{1}$. Other

\footnotetext{
${ }^{1}$ The Oxford Dictionary of Idioms (2nd ed.). Oxford: Oxford University Press. ISBN 0-19-861055-6.
} 
examples are chosen randomly to point out the differences in the linguistic and cultural equivalences, if any, that may be obtained once we translate, simultaneously, the expression mentioned hereunder into French and then into Arabic languages.

\section{ASSUMPTIONS AND ANALYSES}

\subsection{Interpreting and Figures of Speech}

Before developing this study, the researcher would like to define the two major concepts and words discussed in the present research, which are interpreting and the figure of speech.

\subsection{What is Interpreting}

The author of the present study, defines interpreting, in one of his books, entitled 'Theories, Categories and processes of Translation, and Some of their Roles in the Translation of the Holy Qur'an into English, Salsabeel Printing Press, Khartoum' as follows: "In the process of interpreting, the interpreter follows spontaneously and simultaneously the speech of a speaker. The first may be in a booth; the latter delivers his address or speech, in front of a public as in political, scientific or press conferences. Sometimes, the interpretation takes place with a written text, and, in other times, he may have some data on the subject treated in the conference or the gathering concerned. This feature links this act of translation to the written one '(Adam Hamid, 2018).

In consequence it links it to our research. In fact, what makes a figure of speech a challenging expression in interpretation is that it depends on cultural phenomena and allocutions rather than terminological features or items.

It is clear that the purpose or objective of the present study is to illustrate and draw out principles for interpreting figures of speech instantaneously, if possible.

\subsection{Interpreting Figures of Speech: Examples}

\subsubsection{What is a Figure of Speech?}

In this research the author defines a figure of speech as: A word or a phrase that has a meaning different from the literal one suggested by its usage in the daily life language. However, a good interpreter or speaker of a language may guess the meaning of a figure of speech, due to the fact that it is not like an idiom which has a meaning absolutely the linguistic form and the grammatical rules don't suggest.

James Nolan (2005), writes about figures of speech describing them as follows: "Words are often used to form units of meanings in ways that convey more than what the rules of grammar dictate. (p.67)."

So, rendering figures of speech in a TL with the suitable equivalent necessitates intelligence, knowledge and broad culture from the interpreter.

\subsubsection{Complexity and Difficulty of Interpreting Figures of Speech}

Interpreting or translating, simultaneously, a euphemism or a metaphor constitutes a challenging process to the interpreter, unless he/she has a broad, deep linguistic and cultural knowledge of the languages into which, of course, the figure of speech is to be conveyed. However, the interpreter should, look for the equivalent figure of speech in the TL. In case of not having one immediately, as the process of interpretation necessitates, he/she has to focus on the meaning of the figure of speech.

The complexity of interpreting from English into Arabic is that the two languages are not of the same family. Moreover, the cultures of both languages are not identical due to the difference in their respective cultural and linguistic sources.

As we are going to analyse the abovementioned figures of speech in the three (03) languages of the present study, it would be better to treat, briefly, their specifications. French, as known, is a Latin language, but due to the colonisation and the modern international Institutions, it became the second language used worldwide.

The English language, is known to be a Germanic language that had spread in the globe and became, the first language used in the world as regard to the number of countries that speak it, mainly the UK, USA, Canada, Australia, India, Nigeria, and many other educated people or those working with 
international Entities, and organisations.

As the Arabic language is concerned, it is a Semitic language, spoken by twenty-two countries of Africa and Asia and many other peoples of the Islamic religion. The latter aspect gives the Arabic language the feature of a language required for specific religious reasons which are not the subject of our study.

\section{a) How to Interpret the Figures of Speech?}

How to proceed, in case of differences in culture or that the figure of speech in one source language has no direct equivalent in the target language?

As an interpreter translates a speech immediately or instantaneously from one language into another he/she should be well trained to convey the meaning or image that doesn't exist in the target language (TL). The problem is, sometimes, in two languages there may exist ironies or metaphors that are different from the target language. The challenging issue is that the interpreter has only seconds to convey the meaning. In case of shortcomings in the terminology of the interpreter, or the non-existence of the metaphor or the euphemism in his/her language, there will be misleading or literal simultaneous translation that may cause problems. It will be more disastrous interpretation once the meaning is literal such as we shall see, hereunder, giving examples from the three languages treated in this study.

To Interpret The figures of Speech: The interpreter should proceed by rendering the figure of speech of the SL by an equivalent figure of speech in the TL. Or at least, he/she looks for the meaning, in case of lacunae in the TL. As professional interpreter you should not keep silent while the speaker continues to deliver his address or speech. Think of the meaning of the figure of speech to convey in case of remembering a suitable equivalent in the TL. For so doing, the interpreter may apply the method of one-to-one literal Translation (See Newmark 1988, 69). In other words, the interpreter should try to give the figure of a speech, e.g a metaphor by a similar equivalent metaphor, proverb by a proverb, and so on. This is a method to avoid silence while the speaker of the SL speaks or avoid skipping an image, colour etc... that the speaker of the SL desires to convey to the concerned audience. However, if the interpreter tackles the speech or sentences by literal translation the result may be disastrous or a nonsense.

\section{b) Problems that May Render the Interpreting of the Figures of Speech Difficult}

The researcher thinks of some problems that may render the translation of the figures of speech difficult compared to the normal speech or that which contains non-specialised terms or a speech of common aspect. Hereunder are some suggested of these problems:

- Lack of time due to the oral aspect of interpretation. It is evident that a translator has the time to consult dictionaries to look for the exact meaning of the figure of the speech, but the interpreter has no time. Moreover, the problem may be:

- The Non-existence of an equivalent figure of speech in target language TL.

- Some figures of speech, which are concerned with sounds such as alliteration, anaphora, and assonance, will be impossible to translate between an Indo-European Germanic language such as the English language and a Semitic language like the Arabic language. So, alliteration, assonance and the like of figures of speech will not be treated, herein, aiming at suggesting suitable translation, for them. They will, mainly, be translations suggested to look for the meaning.

\subsection{Alliteration}

In alliteration, the same consonant sound is used at the beginning of a series of words to create an effect, like a musical one. It is used in poetry and prose. Hereunder, the researcher shall give the famous example of Sally:

\section{'Sally sells seashells on the seashore'.}

A French interpreter will render this sentence given, here-above, to play on the sounds by:

\section{'Sally vend des coquillages au bord de la mer'}

The interpreter has no way out, but to render the interpretation in Arabic, by the linguistic equivalent looking for the meaning.

Presupposition: 'تبيع سالي القو اقع على ساحل البحر' 
Likewise, writers and speakers use 'assonance' to create the same effect similar to that of 'alliteration'. But 'assonance' is a figure of speech that will not be analysed and developed in this study due to the same problem of differences in the sounds of the English and the Arabic languages, studied herein.

\subsection{Metaphor}

A metaphor is an important figure of speech in which a word or phrase is used to refer to another through hidden similarities, but without using 'as' which is used in simile. If translated literally, a metaphor will lose its colour and objective, due to the inapplicability of the similarities looked for.

To give an example of a metaphor see here-below:

\section{- To fish in troubled water.}

This metaphor would not be easy to interpret in case of working in a conference on a certain political conflict. But, in case of working in a conference on fishing, or if the interpreter comes from a fishing region, he/she may think there is a conflict between two countries as regard to territorial waters and fishing industry. So, he/she may miss the comparison laid in the metaphor. Someone may say: "The context will render the metaphor easy to translate". However, in case of using it in the context of conflicts a problem will raise.

As well, the concerned metaphor may have rendered into French, immediately by:

- Pêcher dans des eaux troublées '; which is the equivalent metaphor that means in French (Profiter
d'une situation quelconque, de troubles, pour s'aligner avec quelqu'un.)

Here, the interpreter should have sufficient knowledge of the culture of the French language to understand that the metaphor means: during periods of trouble, one gets profit of a situation to take side to someone.

Likewise, to simultaneously translate the previous English saying, into the Arabic language, an interpreter may say:

$$
\text { (تصطاد في مياه بهامشكلات أو عكرة وبها أمواج...). }
$$

In the previous suggested interpretation, the interpreter may not have sufficient baggage to convey the implied meaning the metaphor always carries. However, an interpreter with a deep culture and knowledge of the languages concerned, will render the expression by: (أنت) تصطال في البياه (لعكرة).

An interpreter is expected to render, instantaneously, a speech in real time, in a TL. For so doing he/she should be familiar and fluent in the working languages of the concerned gathering or meeting where speeches are to be delivered. If a person grows up in the UK, for example, and he knows the Arabic language well, he/she would have less difficulties to render similar metaphors. As well, in case of growing up in an Arab state, with adequate training, he/she will have the ability and capability for rendering such metaphors into a TL.

\subsection{Translation of the Figures of Speech of the SL by Cultural Equivalent in the TL}

\section{e.g. 'You are the apple of my eye'.}

This phrase means that the person whom the speaker talks about is favourite to him/her, like the pupil of one's own eye. Everybody loves his sight and eyes to the extreme. A question may pass through the mind of a beginner interpreter: Should the interpreter, in case of not knowing an equivalent in the TL, try to look for an equivalent anyway? Or, to translate the concerned figure of speech literally, which is a method to avoid, due to the loss of meaning that may result from such a process?

In French this figure of speech may be translated by:

\section{'Tu es la pomme de mon cœur'}

Which is a non-literal translation. The French speaks of his heart and not his eyes.

In Arabic, it may be rendered by:

' 'أنت إنسان عيني' which is literal. An experienced interpreter looks in the Arabic culture and fiends the unit: 


$$
\text { أو 'أنت نور عبيعي، قانبي، }
$$

The first expression speaks of the favourite person as the 'light of the eye'. No apple is evoked. The second Arabic phrase exists literally and may be extracted from the Islamic culture. It uses the image of 'spring' of the heart.

Another example is extracted from the working field:

\section{e.g. 'He is a horse at firm'}

As the target languages, are the French and the Arabic ones, the researcher suggests that the image of the 'hose ' may be treated in French as follows: turned into an image of the surroundings:

\section{- C'est un cheval au travail, ou : C'est un vrai cheval à l'usine.}

While in Arabic we may have the image of the horse(الحصان) and the camel (الجمل). The 'camel' is the symbol of force, loyalty, patience, endurance etc... for the Arab people.

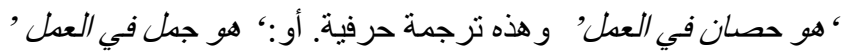

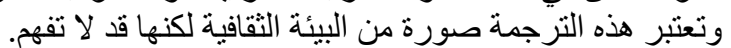

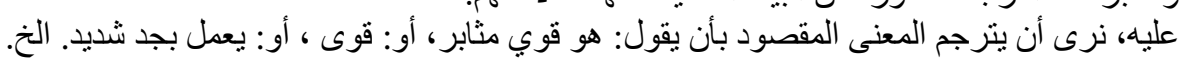

Therefore, the interpreter should avoid using words that may embarrass or discomfort the speaker as well as the audience or listeners: Not to use words from the environment such as 'donkey', or 'bull', to render the word 'horse'.

But anyway, the word 'horse' should not be rendered by a word like 'donkey' or 'monkey' which despite the force of the first and the vivacity in the movement of the latter, are humiliating in Arabic culture.

Likewise, the image of the 'dog', in case used by a speaker, should also be rendered by a cultural equivalent.

$$
\text { تشبيه الكلب بالهرة. أو ربما ترك نفس الججاز لان كثير من العرب خاصة الذين يقطنون افريقيا والصبادين منهم يحبون }
$$

Other metaphors may be rendered by some equivalent ones from the Arabic TL culture, e.g. In a conference on justice, or press conference about justice a speaker may say: 'The Wheel of justice turns slowly.'

In French, this unit will be conveyed by: 'La roue de la justice tourny lentement 'which is a suitable equivalent.

And Arabic interpretation may be literal one as follows:

$$
\text { 'تدور عجلة العدالة ببطء' }
$$

Or an interpreter may render the English unit by:

$$
\text { ' تسينصر المرؤ ولو بعد حين' }
$$

Which means: (You will have justice, even latter on)

Instead of giving a literal interpretation such as:

$$
\text { 'إن عجلة العدالة تدور ببطء' }
$$

We see here that metaphors interpreting may cause and raise problems, be difficult to interpret for the raisons the researcher has given here-above, and which are not exhaustive.

\subsection{Oxymoron}

This figure of speech, announces that there is a contradiction as regard to the words used to convey it.

In case of being interpreter in an international conference, that discusses international trade and other items like sending troupes to a certain area to keep peace, one may translate simultaneously units like:

\section{- The organisation shall send peace keeping 'force'.}

The Oxymoron, appears from the contradiction that emerges as regard to the words 'peace' and 'force'. As if the speaker at the said conference says there will be peace but by deploying and using 
force. Anyway, words such as these mentioned here in the above paragraph could be translated in French as follows:

- L'organisation va envoyer une force pour le maintien de la paix' or 'Force de maintien de la paix'. Here the word 'keep' is rendered, in French, by a linguistic equivalent: 'maintien' despite the fact that the term in the SL is not 'maintain'. Likewise, the Arabic language proceed by linguistic equivalencies: "سترسل المنظمة قوة لحفظ السلام"

The researcher draws the attention of the trainee interpreter that this figure of speech looks like the irony, in some way. Because the speaker uses contradictory terms to designate an idea or a concept.

In the United Nations meetings, mainly those on conflict matters, a certain speaker may use oxymoron to develop his/her speech, e.g:

This speaker may use the words: 'Peace keeping forces'

In a similar situation, an interpreter proceeds by two modalities:

- Rendering the oxymoron by an equivalent in the TL.

- Using a metaphor like the Arabic compound word: القبعات الزرق

While the French interpreter designating the agents and soldiers of the UN by the words: 'Casques Bleus :

\subsection{Euphemism}

In this type of figure of speech, the speaker aims at conveying and idea or information, politely, or in a pleasant manner. Examples are the following:

Talking in a sign language meeting or conference, someone may use words like 'non-hearing people' instead of 'deaf', or describe the people as 'People of special needs '.

Sometimes, a speaker may use the word 'non-seeing ' to refer to a 'blind ' person.

The word 'blind' can be rendered in French by: 'non-voyant' instead of 'aveugle', and the term 'non hearing person' by: 'sourd'.

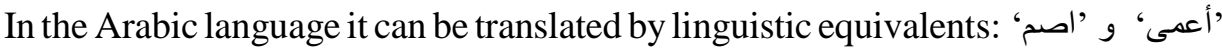

The word 'بصير' means: 'person with good sight or of insight'. Here the role of euphemism is to lighten the heart of the concerned people. The direct and literal translations cause embarrassment. These words, such as 'blind' should be rendered by interpreters by euphemism or as such to avoid embarrassing the audience and the handicapped people concerned by these calamities.

The interpreter who works from time to time with religious men, charity Organisations, benevolent people etc ... encounters euphemism a lot. E.g.

Sometimes it is necessary to give the information directly, mainly when a speaker talks about armed forces or Universities etc... and say:

\section{'The name of Mr. X is not on the list.'}

The French interpreter may render it by: "Son nom ne figure pas sur la list"

رفع اسم فلان من القو ائم بدل عن استعمال كلمة: 'رفد’ أو “طرد، : And in the Arabic language

However, as interpreter since the 1980s, the author suggests, here in this case, a direct translation with clear words to avoid miss-understanding. For example, in Arabic the interpreter should say:

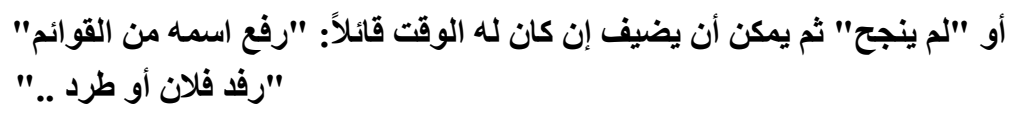

\subsection{Onomatopoeia}

An onomatopoeia word is that used to sound like what it is denoting and describing. However, this simple idea may be a complicated one, once we are in front of words of different cultures. The sound that may be ordinary and normal and describing a certain sound in a source language (SL), may be in a TL, another one, bizarre and not describing or referring to the same sound.

Traditional words that describe some sounds in one SL and are described by other sounds in a $\mathrm{TL}$, despite the fact that in the nature it is the same sound, we have the following ones. Famous examples are: 
The voice of the cock in the English language is as follows: Cocoricodule.

And in the French language: Cocorico.

While in the Arabic language as: 'أو ‘اوع عووووو.' - اله اكبر

Imagine that an interpreter listens to a speaker who imitates the sound of objects falling down, and this speaker wanted to focus on the destroyed object and the effect and said:

"These objects of the antiquity have fallen. They made a noise herd by hundred people, even thousands! 'Baaaang 'Bung', 'crakkkk'.

The interpreter may proceed by many ways:

- Making the same sound of the SL to express the onomatopoeia, or

- Conveying it with an equivalent sound in the TL.

- Or giving the idea by using adjectives describing the massive destruction that happened, but in words not in onomatopoeia.

- A forth solution is to skip the sounds and interpret only the sentences or units according to the meaning that they suggest.

\section{SUMMARY, FINDINGS, RECOMMENDATIONS AND SOLUTIONS}

All through this study and analysis, the researcher found out that interpreting figures of speech constitutes a big difficulty. Some interpreters could find translating the figures of speech analysed herein above difficult. The literature review and the scientific analysis conducted in this study revealed that there are divergences and different points of view as regard to the translation of the figures of speech.

\subsection{Some Solutions of the Problems Underlined, Here-above, by the Researcher}

It is important to point out the problem either it is lexical, stylistic, grammatical or else, then suggests a solution according to the SL and the TL characteristics and specifications. In the case of the figures of speech, it is always the literal translation that causes a problem. The interpreter should look deep in his culture and knowledge to suggest a similar equivalent for the interpretation despite the fact that he/she may not have enough time to suggest a suitable equivalent figure of speech. Nevertheless, all languages, in particular, the UN working languages, could have similar metaphors or messages close to those of the SL, to convey by figures of speech, despite the challenging matter of interpreting them. To avoid such problems, the interpreter should fulfil, know and have the following:

- Rules: There should be ruled to avoid literal translation as well as word-for-word interpretations. This is governed by the rules of grammar and the structure of the SL, as well as the cultural rules that prohibit using taboo words, blasphemy attitudes or terms, words that hurts the listeners, etc...

- Knowledge: To have a good and deep knowledge of both languages concerned in the interpreting process.

- Culture: To learn by heart many proverbs, idioms, metaphors, and other figures of speech of his/her working languages. In our case: The English/French/Arabic languages.

- To be a Real Retour Interpreter: Which means being capable of rendering the meaning of the speech of the SL instantly as if the target language TL is his/her mother tongue. By so doing, to be able to reduce the effect of the mother language while interpreting.

- Anticipation: To proceed by anticipation in case the context of the speech permits it.

- Skipping: To skip any figure of speech not understood, being sure the speaker will develop his/her idea later on, and by so doing the interpreter may come back and interpret the skipped figure of speech by compensation, which means to fill in the gap or the items skipped previously.

- Usage of equivalencies: Comprehending and understanding: To make the audience understand the message: In case of miss-understanding of a translated figure of speech, for any reason, the interpreter should think immediately of an equivalent unit or image such as proverbs or any other cluster, cliché, or idiomatic equivalent that answers the idea or colour (underlying meaning) intended to convey by the speaker to the listeners. 


\section{REFERENCES}

[1] Abdel-Rahman Adam Hamid, (2018), Theories, Categories and processes of Translation, and Some of their Role in the Translation the Holy Qur'an into English, Salsabeel Printing Press, Khartoum.

[2] Abdel-Rahman Adam Hamid, (2005) Recueil des commentaires du Saint Coran, De Yassin à la partie 30, Khartoum. (Explanation \& Commentary of the Holy Quran, Chapter 47: Verse No. 47)

[3] Abdel-Rahman Adam Hamid, (2018), Les perles bien gardées, Abrégé du recueil de l'eImam Boukhari (Q.D.A.), tome: 1/3.

[4] Abdel-Rahman Adam Hamid, (2018) Les perles bien gardées, Abrégé du recueil de l'Imam Boukhari (Q.D.A.), tome: $2 / 3$.

[5] Abdel-Rahman Adam Hamid, (2005), Arabic, English \& French Lexicography, Afro-Tayeb, Khartoum.

[6] Abdel-Rahman Adam Hamid, (2010), Methodology of Research: How to Write a University Research, the Judiciary Printing House, Khartoum.

[7] Chuzhakin, Andrei (2007) "Applied Theory of Interpretation and Note-Taking", "Mir Perevoda 1 to 7", UstnyPerevod,

[8] DELISLE J., l'enseignement de l'interprétation et de la traduction : de la théorie à la pratique, éd., de l'université d'Ottawa, 1981.

[9] Gillies, Andrew (2005) Note-taking for Consecutive Interpreting, ISBN 1-900650-82-7.

[10] Ibn Ginni Ab, al-Fath Utman, Al- Khasais, vol. 1, 2 et 3. éd., Dar Al-khuta Li al-tibaawa al-Nashr, 2ème éd., Beyrouth.

[11] Jones, J.B. (1998) Conference Interpreting Explained, Manchester, St. Jerome.

[12] NEWMARK P., Approach to translation, Oxford 1981.

[13] .........., (1988) A. Textbook of Translation, New York and London: Prentice Hall.

[14] NIDA E. A., Linguistics and ethnology in translation problems, World, Vol. 1:194 - 208.

[15] ------ E. A. , Toward a science of translation, Brill, Legde, 1964.

[16] ------ E. A. , The Theory and Practice of Translation, Leiden, 1969.

[17] Nolan James, (2005), Interpretation, Techniques \& Exercises, Cromewell Press, ISBEN: 1-85359-79OROZAN.

[18] Oxford Dictionary of Idioms (2005), (2nd ed.). Oxford: Oxford UniversityPress. ISBN 0-19-861055-6

[19] Rozan, Jean-François (1956) La Prise de Notes en Interprétation Consécutive, ISBN 2-8257-0053-3.

[20] STEINER G., After Babel: Aspects of language and translation, Oxford University Press, 1977.

[21] Setton, R. (1999) Simultaneous Interpretation. A Cognitive-pragmatic analysis. Amestrdam and Philadelphia: Benjamins.

[22] Suyuti Ab, al-Fadl Aburahman, Al-ashbah Wa al-Nadha'ir, 2e éd. Haydar Abad, 4 Vol., 1940-42.

[23] -------- A., Al-Muzhir fi Ulum Al-Lughawa Anwaaiha, éd., Dar Ihya Al-Kutub Al-Arabiya, 2ème vol. Le Caire.

[24] Taylor-Bouladon, Valerie (2007) Conference Interpreting - Principles and Practice, 2nd Edition ISBN 14196-6069-1

[25] Thaalabi (Ab, Mansur Al-) Kitabfiqh Al-lugha wa Asrar Al-Arab, éd., Maktabat Al- Hayat, Beyrouth.

\section{INTERNET}

[26] https://www.unige.ch/fti/en/ The Faculty of Translation and Interpreting (FTI, formerly ETI), founded in $1941, \ldots$ avec la collaboration du Centre interfacultaire en sciences affectives,) La Faculté de traduction et d'interprétation (FTI, anciennement ETI) est l'une ... avec la collaboration du Centre interfacultaire en sciences affectives, UNIGE.

[27] https://arts.uottawa.ca/translation/ The School of Translation and Interpretation at the University of Ottawa has been offering professional translation courses at the university level since

[28] www.translation.illinois.edu/ University of Illinois at Urbana-Champaign Center for Translation Studies home Center for Translation. 


\section{AUTHORS’ BIOGRAPHY}

Abdel-Rahman Adam Hamid Idris, Department of English and Translation College of Science and Arts, Qassim University, Ar Rass, Saudi Arabia.

Citation: Abdel-Rahman Adam Hamid. "Simultaneous Interpreting of the Figures of Speech: Problems and Solutions" International Journal on Studies in English Language and Literature (IJSELL), vol 7, no. 3, 2019, pp. 47-56. doi: http://dx.doi.org/10.20431/2347-3134.0703007.

Copyright: (c) 2019 Authors. This is an open-access article distributed under the terms of the Creative Commons Attribution License, which permits unrestricted use, distribution, and reproduction in any medium, provided the original author and source are credited. 